\title{
GLIAL CELL LINE-DERIVED NEUROTROPHIC FACTOR GENE THERAPY AMELIORATES CHRONIC HYPERPROLACTINEMIA IN SENILE RATS
}

\author{
G. R. MOREL, ${ }^{a}$ Y. E. SOSA, ${ }^{a}$ M. J. BELLINI, ${ }^{a}$ \\ N. G. CARRI, ${ }^{\text {b }}$ S. S. RODRIGUEZ, ${ }^{\text {a }}$ M. C. BOHN ${ }^{c}$ AND \\ R. G. GOYA ${ }^{a *}$ \\ aInstitute for Biochemical Research at La Plata (INIBIOLP)-Histology \\ $B$, Faculty of Medicine, National University of La Plata CC455, La Plata \\ (1900), Argentina \\ ${ }^{b}$ Instituto Multidisciplinario de Biologia Celular (IMBICE) CC403, La \\ Plata (1900), Argentina \\ ${ }^{\circ}$ Children's Memorial Research Center (CMRC), Northwestern Univer- \\ sity, Chicago, IL, USA
}

\begin{abstract}
Progressive dysfunction of hypothalamic tuberoinfundibular dopaminergic (TIDA) neurons during normal aging is associated in the female rat with chronic hyperprolactinemia. We assessed the effectiveness of glial cell line-derived neurotrophic factor (GDNF) gene therapy to restore TIDA neuron function in senile female rats and reverse their chronic hyperprolactinemia. Young (2.5 months) and senile (29 months) rats received a bilateral intrahypothalamic injection $\left(10^{10} \mathrm{pfu}\right)$ of either an adenoviral vector expressing the gene for $\beta$-galactosidase; (Y- $\beta$ gal and S- $\beta$ gal, respectively) or a vector expressing rat GDNF (Y-GDNF and S-GDNF, respectively). Transgenic GDNF levels in supernatants of GDNF adenovector-transduced N2a neuronal cell cultures were $25 \pm 4 \mathrm{ng} / \mathrm{ml}$, as determined by bioassay. In the rats, serum prolactin (PRL) was measured at regular intervals. On day 17 animals were sacrificed and neuronal nuclear antigen (NeuN) and tyrosine hydroxylase (TH) immunoreactive cells counted in the arcuate-periventricular hypothalamic region. The S-GDNF but not the S- $\beta$ gal rats, showed a significant reduction in body weight. The chronic hyperprolactinemia of the senile females was significantly ameliorated in the SGDNF rats $(P<0.05)$ but not in the $S-\beta$ gal rats. Neither age nor GDNF induced significant changes in the number of NeuN and TH neurons. We conclude that transgenic GDNF ameliorates chronic hyperprolactinemia in aging female rats, probably by restoring TIDA neuron function. () 2010 IBRO. Published by Elsevier Ltd. All rights reserved.
\end{abstract}

Key words: aging, DA neurodegeneration, TIDA neurons, chronic hyperprolactinemia, GDNF, gene therapy.

${ }^{*}$ Corresponding author. Tel: +54-221-425-6735; fax: +54-221-425-0924. E-mail address: rgoya@netverk.com.ar or goya@isis.unlp.edu.ar (R. G. Goya).

Abbreviations: AAV, adeno-associated viral; ARC, arcuate nucleus; AVP, arginine-vasopressin; DA, dopaminergic; EBM, Eagle's Basal Medium; GDNF, glial cell line-derived neurotrophic factor; GFR $\alpha$, glycosylphosphatidylinositol-anchored GDNF receptor-a; GFP, green fluorescent protein; HEK293, human embryo kidney 293 cells; IF, immunofluorescence; mCMV, mouse cytomegalovirus immediate early promoter; mo, months; $\mathrm{PaV}$, paraventricular nucleus; $\mathrm{PeV}$, periventricular nucleus; PRL, prolactin; RAd, recombinant adenoviral vector; TIDA, tuberoinfundibular dopaminergic; $\mathrm{TH}$, tyrosine hydroxylase.
The dopaminergic (DA) neurons of the rat hypothalamus are grouped into two main areas, $A_{12}$ and $A_{14}$, (Dahlström and Fuxe, 1964; Tillet and Kitahama, 1998) with the DA perikarya of the $A_{12}$ area being located in the arcuate $(A R C)$ nucleus and in the periarcuate region (Kawano and Daikoku, 1997). The $A_{14}$ DA neurons are mainly located within the paraventricular $(\mathrm{PaV})$ and periventricular $(\mathrm{PeV})$ nuclei, with a few scattered DA neurons in the anterior ventromedial (AVM) hypothalamic area (Kawano and Daikoku, 1997; Goudreau et al., 1992). The $A_{12}$ area and its corresponding axon terminals constitute the tuberoinfundibular (TIDA) system, whereas the $A_{14}$ area and its fibers are known as the periventricular dopaminergic system. Both systems regulate prolactin (PRL) secretion by exerting a tonic inhibitory control on both PRL secretion and lactotroph proliferation (Ben-Jonathan et al., 1989).

In female rats, aging brings about a progressive dysfunction and loss of TIDA neurons. Degeneration and loss of TIDA neurons during normal aging is associated, in the female rat, with a progressive hyperprolactinemia (Goya et al., 1990) and the development of pituitary prolactinomas (Cónsole et al., 1997). This neuroendocrine pathology provides a unique animal model to assess the efficacy of therapeutic strategies aimed at protecting central DA neurons. Interestingly, Parkinsonian patients were reported to show functional alterations in the hypothalamo-PRL axis (Cusimano et al., 1991).

Glial cell line-derived neurotrophic factor (GDNF), a distant member of the transforming growth factor $\beta$ (TGF $\beta$ ) superfamily, is a potent factor promoting dopamine uptake, survival of embryonic DA neurons and regeneration of mesencephalic DA neurons in rodents and non-human primates treated with dopaminergic neurotoxins (Tomac et al., 1995; Bjorklund et al., 1997; Bowenkamp et al., 1995; Gash et al., 1996; Hoffer et al., 1994). In rats and nonhuman primates, stereotaxic injection in the striatum or in the substantia nigra (SN) of adenoviral, lentiviral or adenoassociated viral (AAV) vectors for GDNF has been shown to protect nigral DA neurons from the toxic action of dopaminergic toxins (Choi-Lundberg et al., 1997; Mandel et al., 1997; Lapchak et al., 1997a; Bilang-Bleuel et al., 1997; Kordower et al., 2000; Connor et al., 1999).

It is well-established that GDNF signals through a multireceptor complex composed of a glycosylphosphatidylinositol-anchored GDNF receptor-a (GDNFR-a) and the receptor tyrosine kinase product of the c-ret proto-oncogene (RET). In situ hybridization studies in the adult rat brain have shown that GDNFR-a, but not RET, is expressed throughout the hypothalamus (Trupp et al., 1997). 
In the arcuate nucleus of the prepuberal rat, the mRNAs for GFR $\alpha-1$ and GFR $\alpha-2$ are strongly expressed whereas the levels of mRNA for RET are low in this region (Burazin and Gundlach, 1999). There is no information on the impact of aging on GDNF receptors in the hypothalamus. Functionally, there is evidence that GDNF is active in the hypothalamus as it induces body weight loss and ameliorates age-related obesity in rats (Lapchak et al., 1997b; Tumer et al., 2006). However, there is no documented information on the possible restorative activity of GDNF on TIDA function in aged female rats. We used an adenoviral vector harboring the gene for rat GDNF in order to implement GDNF gene therapy in the hypothalamus of hyperprolactinemic senile female rats. The present report documents our findings.

\section{EXPERIMENTAL PROCEDURES}

\section{Animals}

Young (2.5 mo.) and senescent (29 mo.) female Sprague-Dawley rats, raised in our institution (INIBIOLP), were used. Animals were housed in a temperature-controlled room $\left(22 \pm 2{ }^{\circ} \mathrm{C}\right)$ on a $14: 10 \mathrm{~h}$ light/dark cycle. Food and water was available ad libitum. In our aging rat colony, the average $50 \%$ survival time for females, studied in groups of 50-60 animals, is 31 months (range 29-33 mo.). All experiments with rats were performed using IACUC approved procedures and Animal Welfare Guidelines of $\mathrm{NIH}$ (INIBIOLP's Animal Welfare Assurance No A5647-01).

\section{Experimental design for in vivo GDNF gene therapy}

Young and senescent females were allotted to a control or experimental group, thus forming four groups: Young control (YC), young experimental (YE), senescent control (SC) and senescent experimental (SE). Beginning at experimental day -3 , a small blood sample $(0.3-0.4 \mathrm{ml})$ was taken from the tail veins of all rats at the indicated times (Fig. 1). Serum was obtained and kept at $-20{ }^{\circ} \mathrm{C}$ for hormone assay. Animals were weighed on different experimental days.

On Experimental day 0, control and experimental animals received bilateral $10-\mu \mathrm{l}$ intrahypothalamic injections containing $3 \times 10^{10}$ pfu of either RAd- $\beta$ gal (an adenoviral vector expressing the gene for $\beta$-galactosidase) or RAd GDNF (a vector expressing the gene for rat GDNF), respectively, with both transgenes under the control of the cytomegalovirus (CMV) promoter. For this purpose, rats were anesthetized by injection of ketamine hydrochloride (40 mg/kg i.p.; Ketalar, Parke Davis, Argentina) and xylazine ( $8 \mathrm{mg} / \mathrm{kg}$ i.m.; Rompum, Bayer, Argentina), and placed in a stereotaxic frame. In order to access the arcuate-periventricular (ARC-PeV) region, the tip of a 26 gauge needle fitted to a $10 \mu \mathrm{l}$ syringe was brought to the following coordinates relative to the bregma: $3.0 \mathrm{~mm}$ posterior, $10.0 \mathrm{~mm}$ ventral and $0.6 \mathrm{~mm}$ right and left (Paxinos and Watson, 1998).

On experimental day 17, animals were placed under deep anesthesia and perfused with phosphate buffered formaldehyde $4 \%,(\mathrm{pH} 7.4)$ fixative. Each brain was removed and trimmed down to a block containing the whole hypothalamus. The block was then serially cut into coronal sections $40 \mu \mathrm{m}$ thick on a freezing microtome.

\section{Immunohistochemistry and immunofluorescence}

In each block, one every six serial sections was selected in order to obtain a set of non-contiguous serial sections spanning the whole hypothalamus. Typically, a whole hypothalamus comprised about 48 coronal sections, thus yielding six sets of eight noncontiguous serial sections ( $240 \mu \mathrm{m}$ apart). For counting purposes, each set was considered as representative of the whole hypothalamus. For each animal, one set of sections was immunohistochemically processed using an anti-tyrosine hydroxylase (TH) monoclonal antibody (Calbiochem INC, La Jolla, CA, USA). Another set was immunohistochemically processed using an antineuronal nuclear antigen (NeuN) marker monoclonal antibody (MAB377, Chemicon Inc., Temecula, CA, USA). For detection, the Vectastain ${ }^{\circledR}$ Universal $A B C$ kit (Vector Laboratories, Inc., Burlingame, CA, USA) employing 3,3-diamino benzidine tretrahydrochloride (DAB) as chromogen, was used. Sections were dehydrated, mounted and used for image analysis.

In brain sections of some of the rats, GDNF was detected by immunofluorescence (IF) using a primary mouse monoclonal antibody against human GDNF (MAb212, R\&D Systems, Minneapolis, MN, USA) and a goat anti mouse IgG antibody conjugated to Alexa $488 \AA$ (Invitrogen, Argentina). Representative hypothalamic sections were photographed with a $20 \times$ objective, whose space calibration corresponded $0.625 \mu \mathrm{m} /$ pixel with a resolution of $1360 \times 1024$ pixels with a pixels depth of 24 bits RGB.

\section{Image analysis}

The hypothalamic A12 and A14 areas were captured using an Olympus DP70 digital video camera attached to an Olympus BX51 microscope (Tokyo, Japan). Sections were analyzed using the ImagePro Plus (IPP TM) v5.1 image analysis software (Media Cybernetics, Silver Spring, MA, USA). The counting of TH-immu-

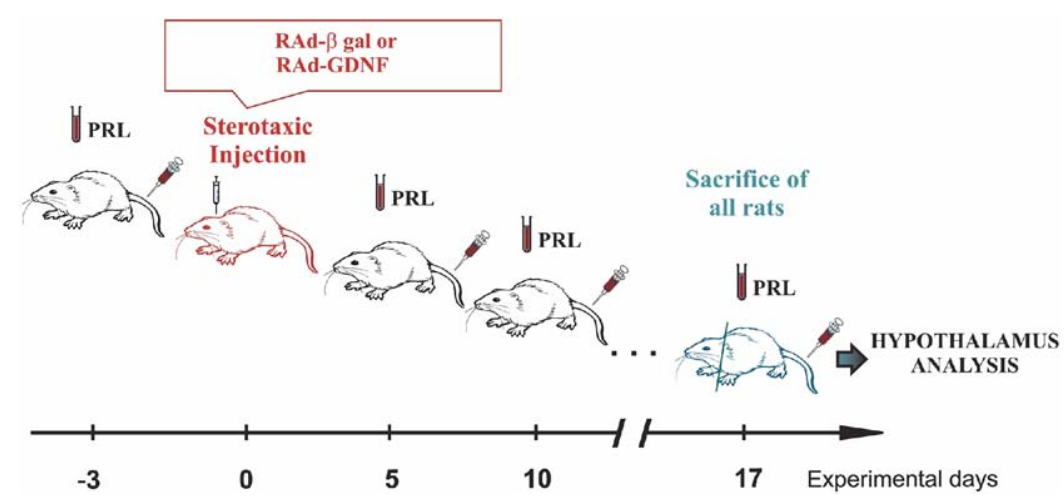

Fig. 1. Experimental design for GDNF gene therapy in the hypothalamus of young and senile female rats. Animals were bled at experimental days $-3,5,10$ and 17 , taking $0.3-0.4 \mathrm{ml}$ blood from the tail veins in each sampling. RAd- $\beta$ gal (controls) or RAd-GDNF (experimental) were stereotaxically injected in the hypothalamus of young and senile animals on experimental day 0 . See Results for further details. For interpretation of the references to color in this figure legend, the reader is referred to the Web version of this article. 
noreactive (TH-IR) and NeuN-immunoreactive ( $\mathrm{NeuN}-\mathrm{IR}$ ) neurons was carried out by the optical fractionator method (West et al., 1991) on the sections corresponding to the ARC-PeV region which is located between coordinates -1.30 up to -4.00 from the bregma (Paxinos and Watson, 1998). In each section of a given hypothalamic set (see above) optical dissectors were delineated. They were $300 \times 300 \times 15 \mu \mathrm{m}^{3}$ cubes spaced in a systematic random manner $600 \mu \mathrm{m}$ apart and offset $3 \mu \mathrm{m}$ from the section surface.

\section{Hormone assay}

For all hormones, serum samples were assayed in duplicate. Serum PRL was measured by a specific radioimmunoassay (RIA), using the rat materials provided by Dr. A. F. Parlow, Pituitary Hormones and Antisera Center, Harbor-UCLA Medical Center, Torrance, CA, USA. Serum PRL was expressed in terms of NHPP rPRL Reference Preparation-3.

\section{Bioassay for GDNF}

The neurotrophic bioactivity generated by RAd-GDNF was estimated by bioassay of supernatants from N2a (mouse neuroblastoma) cells incubated for 3 days with either RAd-GDNF or RAd$\beta \mathrm{gal}$ (control) at a multiplicity of infection (MOI) of 2 .

The bioassay was performed according to the protocol originally described by Ebendal (1989) slightly modified by Carri et al. (1998), using highly sensitive neurons from explanted sympathetic ganglia from chick embryo placed in a 3D collagen gel. Briefly, eggs from domestic hens (white Leghorn) were incubated at $38{ }^{\circ} \mathrm{C}, 60 \%$ relative humidity, and turned every $6 \mathrm{~h}$. Sympathetic ganglia were obtained from day 8-9 embryos, and placed in Eagle's Basal Medium (EBM) at room temperature and the dissections were performed under sterile conditions using a stereomicroscope placed in a horizontal laminar flow cabinet. After removal of surrounding tissues, ganglia were taken with the aid of a tweezer for easy handling and placed in collagen gels that were prepared according to Elsdale and Bard (1972). Ganglia were placed on a drop of culture medium in the center of plastic culture dishes (35 mm in diameter) and then were filled with $0.1 \mathrm{ml}$ collagen medium mixture which was allowed to set. The ganglia were explanted inside the gel which seemed to facilitate nerve fiber spread. For routine purposes, the nutrient medium of the gel was EBM supplemented with $1 \%$ fetal calf serum. A further $0.1 \mathrm{ml}$ of EBM or N2a cell supernatant was added to the gel in order to expose the ganglia to bioactive activity of the preparation tested and explants were incubated for 2 days without replacing the medium, at $37.5{ }^{\circ} \mathrm{C}, 80 \%$ relative humidity, in an atmosphere containing $5 \% \mathrm{CO}_{2}$.

Neurotrophic activity was determined by scoring fiber outgrowth on a semiquantitative scale, grading fiber outgrowth from 0 (lowest) to 5 (highest) as described in the original method (Ebendal, 1989). A standard curve was performed using recombinant human GDNF (Peprotech Inc., Rocky Hill, NJ, USA) at final concentrations ranging from 5 to $50 \mathrm{ng} / \mathrm{ml}$.

Some ganglia cultured for 2 days were fixed in $4 \%$ formaldehyde in phosphate buffer $(0.1 \mathrm{M}, \mathrm{pH} 7.4)$ for $1 \mathrm{~h}$, postfixed in the same fixative for another hour and the complete whole mounth preparations photographed with an inverted microscope (Leitz Diavertl using dark-field, phase contrast or epifluorescense). For inmunofluorescence, the 3D ganglion-collagen-gel preparations were incubated with a rabbit serum anti-NF200 neurofilament (1:100; Amersham, UK), using a Cy2-conjugated anti-rabbit IgG serum (1:500; Amersham) as second antibody.

\section{Statistical analysis}

The analysis of variance (ANOVA) was used to evaluate group differences. Tukey's method was chosen as a post hoc test.

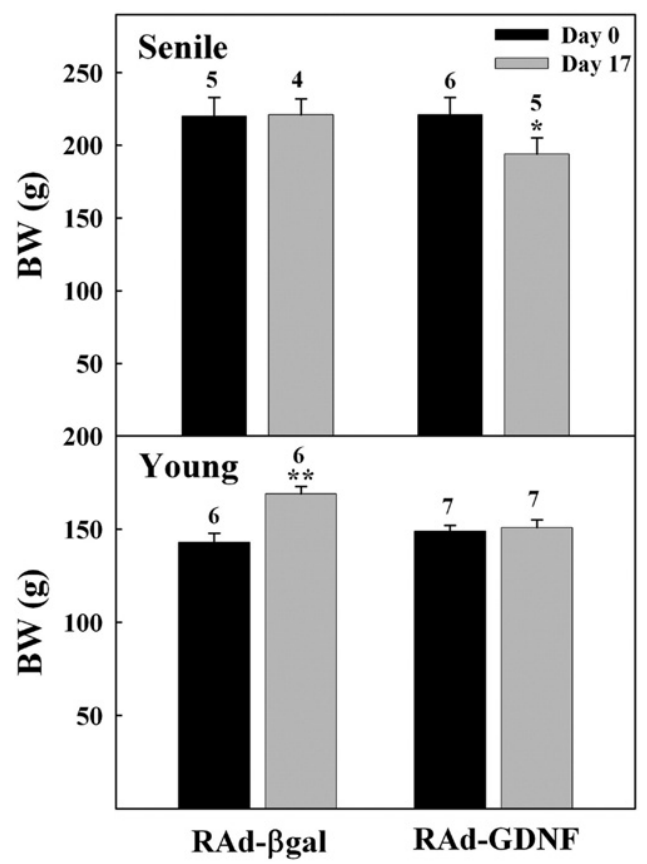

Fig. 2. Effect of 17-day hypothalamic GDNF gene therapy on body weight of young and senile rats. Note that young control rats were still growing whereas the control senile animals had long reached growth stasis. Bars and numbers on columns represent SEM and $n$-values, respectively. ${ }^{*} P<0.05 ;{ }^{* *} P<0.01$.

Significant differences between rat groups were defined as those with a $P<0.05$. Data were expressed as $\times \pm$ SEM.

\section{RESULTS}

\section{Effect of hypothalamic GDNF gene transfer on body weight and serum PRL}

At the end of the treatment, the rats injected with RAdGDNF showed a lower body weight than the corresponding RAd- $\beta$ gal controls (Fig. 2). Although this body weight difference was evident at all times after vector injection, all rats (control and experimental) lost weight during the first days post-stereotaxic surgery. As expected, at the beginning of the study all senile rats were significantly hyperprolactinemic (all senile vs. all young, $55 \pm 4$ (13) vs. $28 \pm 1$ (11) $\mathrm{ng} / \mathrm{ml}$, respectively; $P<0.01$ ). At the end of the treatment, serum PRL levels showed a substantial (41\%) fall in the senile rats as compared to RAd- $\beta$ gal counterparts, whereas in the young rats the treatment elicited only a mild reduction in serum PRL (Fig. 3).

\section{Transgenic GDNF bioactivity}

After two-day incubation with purified recombinant hGDNF ganglionar explants showed, as expected, good survival and robust neurite outgrowth (data not shown). A similar stimulatory action on explant survival and neurite outgrowth was observed in sympathetic ganglia exposed to supernatants from N2a cells incubated with RAd-GDNF (Fig. 4, right main panels). Based on a GDNF standard curve for fiber outgrowth, the concentration of bioactive 


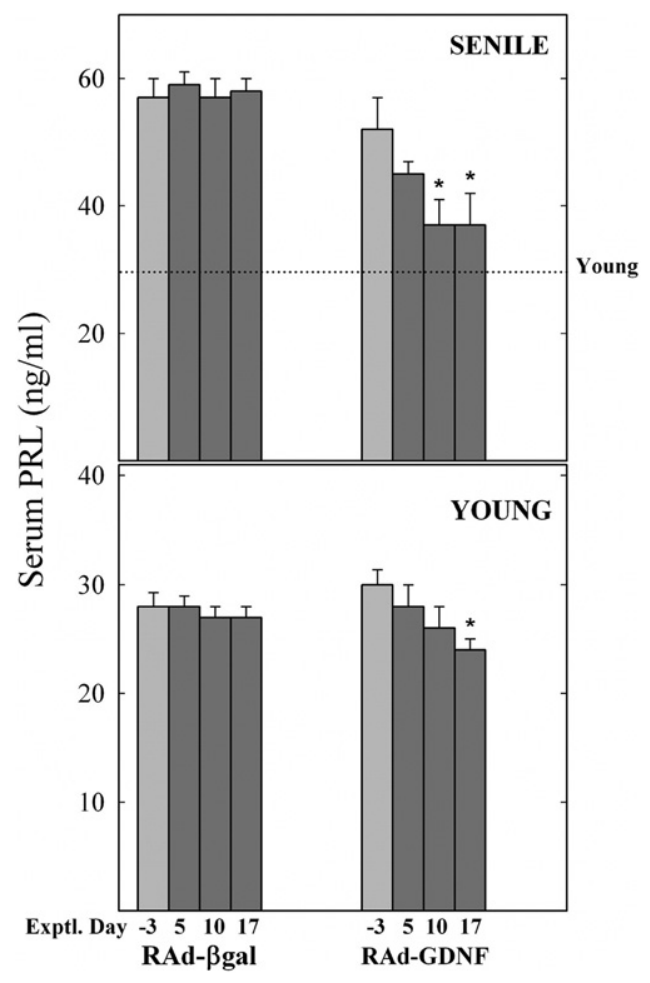

Fig. 3. Effect of intrahypothalamic injection of RAd- $\beta$ gal or RAdGDNF on serum PRL profiles in young and senile rats. The lower and upper panels correspond to young $(2.5 \mathrm{mo}$.) and senile $(29 \mathrm{mo}$.) females, respectively. The columns in light gray (Exptl. Day -3) indicate pre-injection PRL levels. Note that at pre-injection time all senile females were hyperprolactinemic as compared with reference values from intact young female rats (dotted line). YC, YE, SC and SE correspond to young control, young experimental, senescent control and senescent experimental, respectively. The number of animals was six, seven, five and six, for YC, YE, SC and SE, respectively. Bars over columns represent SEM values. Asterisks over columns indicate significant difference from day -3 values.

GDNF in the RAd-GDNF cell supernatants was estimated to be $25 \pm 4 \mathrm{ng} / \mathrm{ml}(n=2)$ and nondetectable in the RAd$\beta$ gal cell supernatants.

\section{Immunoreactive transgenic GDNF expression}

Seventeen-day GDNF gene therapy was implemented according to the experimental design described in Experimental Procedures (Fig. 1). No GDNF immunoreactive (GDNF-IR) cells were detected in the hypothalamus of intact young and senile rats (data not shown). Injection of both RAd- $\beta$ gal and RAd-GDNF in the ARC-PeV region of young and senile rats induced the appearance of a substantial number of GDNF-IR cells around the injection area. However, 10 days post vector injection only the RAd-GDNF-injected animals still showed GDNF-IR cells in the ARC-PeV region (Fig. 4).

\section{Lack of effect of GDNF on hypothalamic TH-IR and NeuN-IR neuron number}

The TH-IR and NeuN-IR neuronal populations (Figs. 5 and 6, respectively) were morphometrically assessed in the
ARC-PeV region of young and senile rats. The number of neither NeuN-IR nor TH-IR neurons in the ARC-PeV nuclei was significantly affected by GDNF gene therapy at any age (Table 1). NeuN-IR cells showed a trend $(P<0.08)$ towards an age-related reduction in this region.

\section{DISCUSSION}

A number of in vivo models have been developed for the study of the pathophysiology of Parkinson's disease, as well as for the assessment of new therapeutic strategies for this devastating disease. They include the use of neurotoxins to lesion nigral DA neurons in primates and rodents and the generation of transgenic models overexpressing $\alpha$-synuclein (Shimohama et al., 2003). Although each of these paradigms has provided valuable information for the understanding of Parkinson's disease, they share a significant limitation namely, that the neurological lesions they study are caused by experimental manipulations rather than by aging, the only unequivocal risk factor for Parkinson's disease (de Rijk et al., 1995; Mayeux et al., 1995). In this context, the TIDA system of the aging female rat emerges as a relevant model of spontaneous and progressive age-related DA dysfunction. Furthermore, the functional status of TIDA neurons can be readily monitored in the rats by measuring circulating PRL levels. The advantages of the neuroendocrine system for the evaluation of gene therapy strategies in the CNS has already been demonstrated in the Brattleboro rat, a mutant lacking arginine-vasopressin (AVP) which is used as a model of diabetes insipidus (Valtin, 1992). When an adenoviral vector encoding the rat AVP cDNA was stereotaxically injected into the supraoptic nucleus of Brattleboro rats, a substantial expression of AVP in magnocellular cells as well as the presence of immunohistochemically detectable AVP in their axons projecting to the posterior pituitary were detected. Measurement of urine output and urine osmolality showed that the symptoms of diabetes insipidus in the Brattleboro rats were significantly reduced for up to 4 months after injection of the viral vector (Geddes et al., 1997).

In addition to a slight loss of hypothalamic DA neurons (see below), the senile female rat also shows a moderate (33\%) but significant loss of TH-IR nigral neurons as well as a marked decline in motor performance relative to young counterparts (Sanchez et al., 2008). The aging Rhesus monkey constitutes another (less amenable) model of spontaneous DA nigral neuron loss. Thus, it has been reported that 25-27 years old monkeys show a 50\% TH immunoreactive and a $33 \%$ dopamine transporter-immunoreactive nigral neuron loss compared to 3-5 year old counterparts. These changes were associated with impairment of fine motor task performance and home cage activity (Emborg et al., 1998).

The present report constitutes a follow up study on the ability of different neurotrophic factors to restore the function of aged TIDA neurons. We have previously documented that insulin-like growth factor I (IGF-I) gene therapy in the hypothalamus of senile female rats is highly 

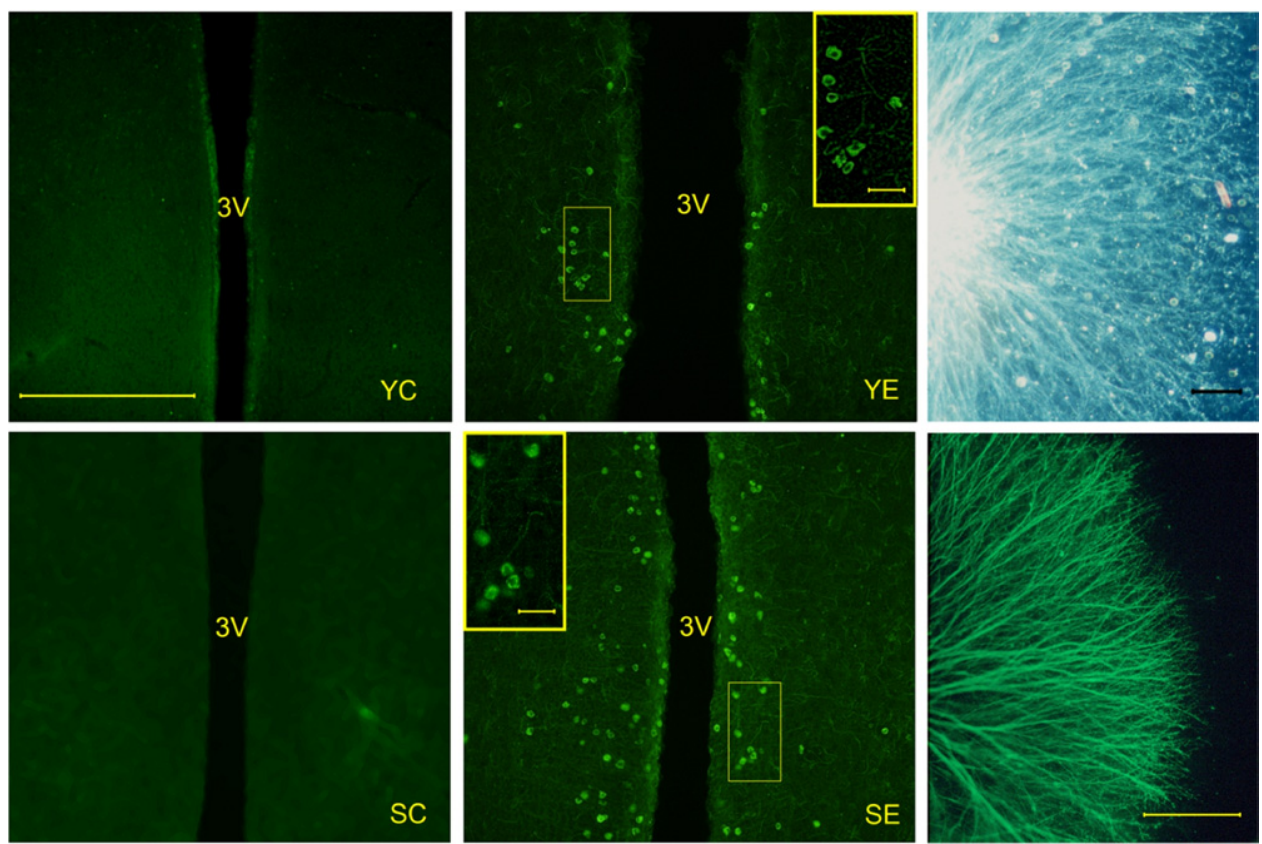

Fig. 4. In vivo immunoreactivity and in vitro bioactivity of transgenic GDNF. Left and central main panels. Rats were perfused and processed for GDNF IF 10 days after vector injection in the hypothalamus. YC, YE, SC, and SE correspond to young control, young experimental, senescent control and senescent experimental rats, respectively. Insets in central panels show the framed areas at higher magnification. Right main panels show GDNF-induced fiber outgrowth in 9-day chick embryo sympathetic ganglia cultured for 2 days in the presence of supernatants from N2a cells incubated with RAd-GDNF. Upper panel shows a dark field image; lower panel shows IF for NF200 neurofilament protein. For further details see Experimental Procedures. Scale bar for left and center main panels corresponds to $200 \mu \mathrm{m}$. Scale bars in central panel insets correspond to $25 \mu \mathrm{m}$. Scale bars in right main panels correspond to $500 \mu \mathrm{m}$. For interpretation of the references to color in this figure legend, the reader is referred to the Web version of this article.

effective in restoring hypothalamic DA neuron function and correct the chronic hyperprolactinemia associated with depressed TIDA neuron function in old rats (Hereñú et al.,
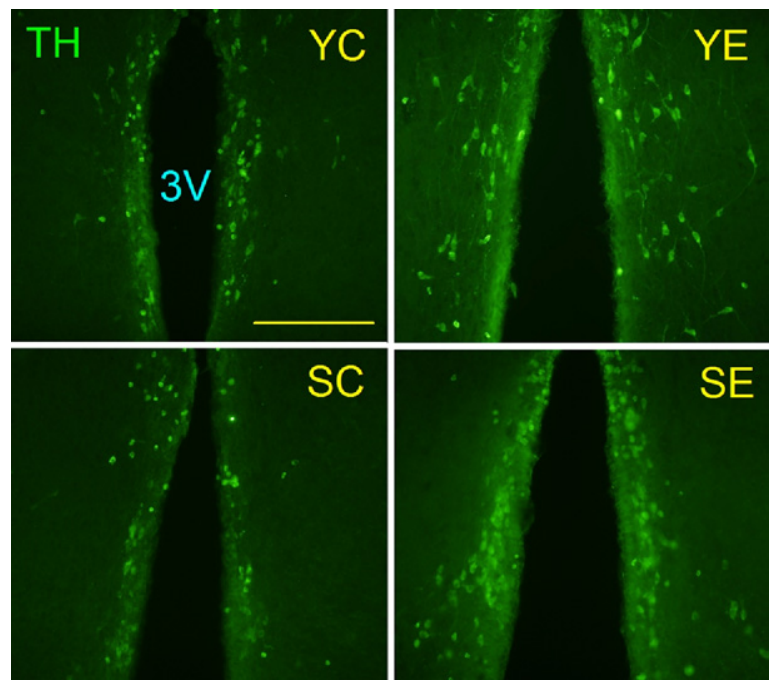

Fig. 5. Tyrosine hydroxylase immunoreactive neurons in the hypothalamus of control and experimental young and senile rats. Animals were sacrificed 17 days post vector injection and their hypothalami submitted to IF for TH. The panels show the arcuate-periventricular region. Scale bars correspond to $200 \mu \mathrm{m}$. Other details are as in Fig. 4. For interpretation of the references to color in this figure legend, the reader is referred to the Web version of this article.
2007). The present results show that GDNF is also able to reduce the chronic hyperprolactinemia of senile females albeit to a lesser extent than IGF-I. An effective in vivo

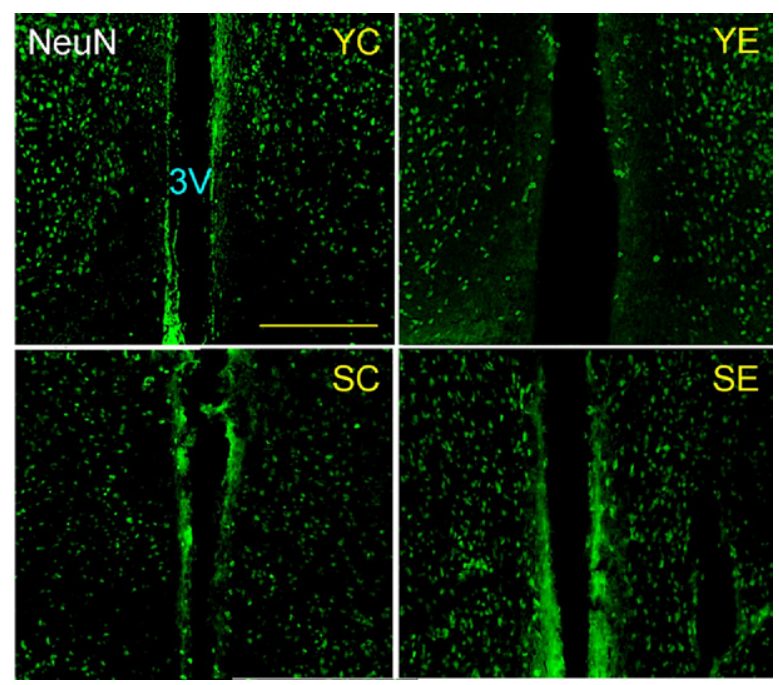

Fig. 6. NeuN immunoreactive neurons in the hypothalamus of control and experimental young and senile rats. Animals were sacrificed 17 days post vector injection and their hypothalami submitted to IF for the NeuN mature neuron marker. The panels show the arcuate-periventricular region. Scale bars correspond to $200 \mu \mathrm{m}$. Other details are as in Fig. 4. For interpretation of the references to color in this figure legend, the reader is referred to the Web version of this article. 
Table 1. Effect of 17-day hypothalamic GDNF gene therapy on TH and NeuN neuron number in the ARC-PeV of young and senile female rats

\begin{tabular}{lrll}
\hline ARC-PeV nucleus & & & \\
\hline Exptl. group & $\begin{array}{l}\text { TH neuron } \\
\text { number }\end{array}$ & $\begin{array}{l}\text { NeuN neuron } \\
\text { number }\end{array}$ & $\begin{array}{l}\text { TH/NeuN } \\
\text { ratio }\end{array}$ \\
\hline Y- $\beta$ gal (3) & $1116 \pm 198$ & $3306 \pm 427$ & 0.34 \\
Y-GDNF (4) & $942 \pm 102$ & $3534 \pm 240$ & 0.27 \\
S- $\beta$ gal (4) & $1008 \pm 120$ & $3048 \pm 90$ & 0.33 \\
S-GDNF (3) & $846 \pm 216$ & $2910 \pm 360$ & 0.29 \\
\hline
\end{tabular}

Data are expressed as $\times \pm$ SEM. The one-way ANOVA for TH neurons was NS $(P>0.20)$ as was the ANOVA for NeuN neurons $(P>0.05)$. Consequently, no post ANOVA tests were carried out.

${ }^{\text {a }}$ Represents the number of animals assessed per group.

expression of transgenic GDNF by RAd-GDNF is indicated by the positive immunoreactivity for GDNF in the hypothalamus of the RAd-GDNF-treated rats. The robust fiber outgrowth induced in chick embryo sympathetic ganglia by supernatants of cells incubated with RAd-GDNF further confirms that our vector expresses significant levels of bioactive GDNF as the bioassay is highly sensitive for this factor (Ebendal et al., 1995).

The RAd-GDNF treatment elicited only a mild reduction in serum PRL in the young rats. The rats treated with RAd-GDNF showed a lower body weight than the corresponding controls which is consistent with the known body weight reducing activity of GDNF in Parkinsonian patients and monkeys (Nutt et al., 2003; Zhang et al., 1997) as well as in normal rats (Lapchak et al., 1997). In a study in which GDNF gene therapy was implemented in the rat hypothalamus, injection of an AAV expressing GDNF was able to ameliorate the obesity of 23-month old male Fischer 344 rats. The weight loss, which occurred in both young and old animals, was associated with decreased food intake and increased energy expenditure but not with changes in hypothalamic dopamine or TH protein levels (Tumer et al., 2006). Despite the differences in age, sex and strain, between this study and ours, the findings are in agreement concerning the effect of intrahypothalamic GDNF on body weight in young and old rats. In both studies an initial reduction in body weight was observed in both young and old control rats injected with a vector expressing a reporter gene. In our animals, we noticed that intrahypothalamic injection of RAd- $\beta$ gal (or even saline) induced a significant but transient expression of GDNF around the injection area (data not shown). Therefore, we believe that the initial body weight loss observed in the control animals may be due not only to the effect of surgery but also to the action of endogenous GDNF expression. It has been recently reported that injection in the $\mathrm{SN}$ of 25-month old male Fischer 344 rats of an AAV expressing GDNF induced a more profound body weight loss than injection of the same vector in the hypothalamus (Manfredsson et al., 2009). The authors suggest that this effect may be mediated by activation of corticotropin releasing hormone neurons in the parvocellular division of the $\mathrm{PaV}$ nucleus.

In early studies, TIDA neuron function was reported to decline during aging in rats, with a marked reduction in hypothalamic, median eminence and neurointermediate lobe DA content in old (24-26 mo.) compared to that of young (4 mo.) rats (Porter et al., 1980). More significant, the rate of DA secretion into the hypophysial portal blood of aged (20-26 mo.) male and female rats was found to decline drastically when compared with young (2-4 mo.) counterparts (Reymond and Porter, 1981; Gudelsky et al., 1981). Although the above age-related alterations in hypothalamic DA secretion were ascribed to a functional decline of TIDA neurons rather than to TIDA neuron loss (Porter et al., 1994), more recent work in very old female rats (32 mo.) showed that at extreme ages, some DA neuron loss $(26 \%)$ does occur in the rat hypothalamus (Sanchez et al., 2003). The significant hyperprolactinemia of our senile rats in the face of minimal or no TIDA neuron loss supports the hypothesis proposed by others, namely that in the aging female rat most TIDA neurons survive but become progressively dysfunctional (Porter et al., 1994). In this context, the significant reversion of chronic hyperprolactinemia effected by RAd-GDNF, but not RAd- $\beta$ gal, treatment in the senile females, suggests that expression of transgenic GDNF in the hypothalamus of the aged animals partially restored (directly or indirectly) DA neuron function without significantly affecting DA neuron number.

In aged Rhesus monkeys GDNF gene therapy using a lentiviral vector was reported to increase the number of TH-IR nigral neurons by $85 \%$ relative to control old animals (Kordower et al., 2000). In another study in which AAVGDNF was injected unilaterally into the putamen of aged Rhesus monkeys, the number of nigral DA neurons, DA turnover and fiber density were increased only on the treated side (Johnston et al., 2009). These findings are in contrast to our results in the rat hypothalamus in which there was no significant effect of GDNF on TIDA neuron number in the aged rats. Whether the findings in old Rhesus monkeys indicate that GDNF induces DA neurogenesis in the SN (but not in the hypothalamus) remains to be investigated. An alternative explanation may be that in aged animals, a portion of the nigral DA, but not TIDA, neurons have depressed expression of $\mathrm{TH}$, which is strongly upregulated by GDNF in the former but not in the latter. Our findings, when considered together with those from the other studies summarized here, suggest that the function of DA neurons in both the nigra and the hypothalamus of aged animals can be restored by GDNF.

The present study describes the implementation of restorative gene therapy in a little explored animal model of age-related central DA neuron dysfunction. Using this paradigm we demonstrated that GDNF gene therapy in the hypothalamus of hyperprolactinemic senile female rats is effective in ameliorating their chronic hyperprolactinemia, possibly by stimulating TIDA neuron function.

Acknowledgements-This study was supported in part by a Luis Santalo grant from the Argentine Research Council (CONICET), grant\# PICT38214 from the (Argentine) National Agency for the Promotion of Science and Technology and NIH grant R01AG029798-2 from the National Institute on Aging (NIA) and 
the Fogarty International Center (FIC) to RGG and MCB. RGG and NGC are Research Career scientists of CONICET.

\section{REFERENCES}

Ben-Jonathan N, Arbogast LA, Hyde JF (1989) Neuroendocrine regulation of prolactin release. Prog Neurobiol 33:399-477.

Bilang-Bleuel A, Revah F, Colin P, Locquet I, Robert JJ, Mallet J, Horellou P (1997) Intrastriatal injection of an adenoviral vector expressing glial cell line-derived neurotrophic factor prevents dopaminergic neuron degeneration and behavioral impairment in a rat model of Parkinson disease. Proc Natl Acad Sci USA 94: $8818-8823$

Bjorklund A, Rosenblud C, Winkler C, Kirik D (1997) Studies of neuroprotective and regenerative effects of GDNF in a partial lesion model of Parkinson's disease. Neurobiol Dis 4:186-200.

Bowenkamp KE, Hoffman AF, Gerhardt GA, Henry MA, Biddle PT, Hoffer BJ, Granholm ACE (1995) Glial cell line-derived neurotrophic factor supports survival of injured midbrain. dopaminergic neurons. J Comp Neurol 355:479-489.

Burazin TCD, Gundlach AL (1999) Localization of GDNF/neurturin receptor (c-ret, GFR $\alpha$-1and $\alpha-2$ ) mRNAs in postnatal rat brain: differential regional and temporal expression in hippocampus, cortex and cerebellum. Brain Res Mol Brain Res 73:151-171.

Carri NG, Bengtsson H, Charette MF, Ebendal T (1998) BMPR-II expression and OP-1 effects indeveloping chicken retinal explants. Neuroreport 9:1097-1101.

Choi-Lundberg DL, Lin Q, Chang YN, Chiang YL, Hay CM, Mohajeri H, Davidson BL, Bohn MC (1997) Dopaminergic neurons protected from degeneration by GDNF gene.therapy. Science 275:838-841.

Connor B, Kozlowski DA, Schallert T, Tillerson JL, Davidson BL, Bohn MC (1999) Differential effects of glial cell line-derived neurotrophic factor (GDNF) in the striatum and substantia nigra of the aged Parkinsonian rat. Gene Ther 6:1936-1951.

Cónsole G, Gómez Dumm CLA, Brown OA, Goya RG (1997) Sexual dimorphism in the age changes of the pituitary lactotrophs in rats. Mech Ageing Dev 95:157-166.

Cusimano G, Capriani C, Bonifati V, Meco G (1991) Hypothalamopituitary function and dopamine dependence in untreated parkinsonian patients. Acta Neurol Scand 83:145-150.

Dahlström A, Fuxe K (1964) Evidence for the existence of monoamine containing neurons in the central nervous system. I. Demonstration of monoamines in the cell bodies of brain stem neurons. Acta Physiol Scand 62:1-55

de Rijk MC, Breteler MM, Graveland GA, Ott A, Grobbee DE, van der Meche F, Hofman A (1995) Prevalence of Parkinson's disease in the elderly: the Rotterdam study. Neurology 45:2143-2146.

Ebendal T (1989) Use of collagen gels to bioassay nerve growth factor activity. In: Nerve growth factors. IBRO handbook series. Methods in the Neurosciences, Vol. 12. (Rush RA, ed), pp 81-93. Chichesterl: John Wiley and Sons Ltd.

Ebendal T, Tomac A, Hoffer BJ, Olson L (1995) Glial cell line-derived neurotrophic factor stimulates fiber formation and survival in cultured neurons from peripheral autonomic ganglia. J Neurosci Res 40:276-284.

Elsdale T, Bard J (1972) Collagen substrata for studies on cell behavior. J Cell Biol 54:626-637.

Emborg ME, Ma SY, Mufson EJ, Levey AI, Taylor MD, Brown WD, Holden JE, Kordower JH (1998) Age-related declines in nigral neuronal function correlate with motor impairments in rhesus monkeys. J Comp Neurol 401:253-265.

Gash DM, Zhang Z, Ovadia A, Cass WA, Yi A, Simmerman L, Russell D, Martin D, Lapchak PA, Collins F, Hoffer BJ, Gerhardt GA (1996) Functional recovery in parkinsonian monkeys treated with GDNF. Nature 380:252-255.

Geddes BJ, Harding TC, Lightman SL, Uney JB (1997) Long-term gene therapy in the CNS: reversal of hypothalamic diabetes insip- idus in the Brattleboro rat by using an adenovirus expressing arginine vasopressin. Nat Med 3:402-1404.

Goudreau JL, Lindley SE, Lookingland KJ, Moore KE (1992) Evidence that hypothalamic periventricular dopamine neurons innervate the intermediate lobe of the rat pituitary. Neuroendocrinology 40:145-151.

Goya RG, Lu JKH, Meites J (1990) Gonadal function and pituitary and mammary pathology in the aging rat. Mech Ageing Dev 56:77-88.

Gudelsky GA, Nansel DD, Porter JC (1981) Dopaminergic control of prolactin secretion in the aging male rat. Brain Res 204:446-450.

Hereñú CB, Cristina C, Rimoldi OJ, Becú-Villalobos D, Cambiaggi V, Portiansky EL, Goya RG (2007) Restorative effect of insulin-like growth factor I gene therapy in the hypothalamus of senile rats with dopaminergic dysfunction. Gene Ther 14:237-245.

Hoffer BJ, Hoffman A, Bowenkamp K, Huettl P, Hudson J, Martin D, Lin LFH, Gerhardt GA (1994) Glial cell line-derived neurotrophic factor reverses toxin-induced injured to midbrain dopaminergic neurons in vivo. Neurosci Lett 182:107-111.

Johnston LC, Eberling J, Pivirotto P, Hadaczek P, Federoff HJ, Forsayeth $\mathrm{J}$ (2009) Clinically relevant effects of AAV2-GDNF on the dopaminergic nigrostriatal pathway in aged rhesus monkeys. Hum Gene Ther 20:497-510.

Kawano H, Daikoku S (1997) Functional topography of the rat hypothalamic dopamine neuron systems: retrograde tracing and immunohistochemical study. J Comp Neurol 265:242-253.

Kordower JH, Emborg ME, Bloch J, Ma SY, Chu Y, Leventhal L, McBride J, Chen EY, Palfi S, Roitberg BZ, Brown WD, Holden JE, Pyzalski R, Taylor MD, Carvey P, Ling Z, Trono D, Hantraye P, Deglon N, Aebischer P (2000) Neurodegeneration prevented by lentiviral vector delivery of GDNF in primate models of Parkinson's disease. Science 290:767-773.

Lapchak PA, Araujo DM, Hilt DC, Sheng J, Jiao S (1997a) Adenoviral vector-mediated GDNF gene therapy in a rodent lesion model of late stage Parkinson's disease. Brain Res 777:153-160.

Lapchak PA, Miller PJ, Jiao S (1997b) Glial cell line- derived neurotrophic factor induces the dopaminergic and cholinergic phenotype and increases locomotor activity in aged Fischer 344 rats. Neuroscience 77:745-752.

Mandel RJ, Spratt SK, Snyder RO, Leff SE (1997) Midbrain injection of recombinant adeno-associated virus encoding rat glial cell-derived neurotrophic factor protects nigral neurons in a progressive 6-hydroxydopamine-induced degeneration model of Parkinson's disease in rats. Proc Natl Acad Sci U S A 94:14083-14088.

Manfredsson FP, Tumer N, Erdos B, Landa T, Broxson CS, Sullivan LF, Rising AC, Foust KD, Zhang Y, Muzyczka N, Gorbatyuk OS, Scarpace PJ, Mandel RJ (2009) Nigrostriatal rAAV-mediated GDNF overexpression induces robust weight loss in a rat model of age-related obesity. Mol Ther 17:980-991.

Mayeux R, Marder K, Cote LJ, Denaro J, Hemenegildo N, Mejia $H$, Tang MX, Lantigua R, Wilder D, Gurland B (1995) The frequency of idiopathic Parkinson's disease by age, ethnic group and sex in northern Manhattan, 1988-1993. Am J Epidemiol 142:820-827.

Nutt JG, Burchiel KJ, Comella CL, Jankovic J, Lang AE, Laws ER Jr, Lozano AM, Penn RD, Simpson RK Jr, Stacy M, Wooten GF (2003) Randomized, double-blind trial of glial cell line-derived neurotrophic factor (GDNF) in PD. Neurology 60:69-73.

Paxinos G, Watson C (1998) The rat brain in stereotaxic coordinates. San Diego, CA: Academic Press.

Porter JC, Aguila-Mansilla N, Ramin SM, Kedzierski W (1994) Secretion by hypothalamic dopaminergic neurons of the aged brain. Neurobiol Aging 15:535-539.

Porter JC, Nansel DD, Guselsky GA, Reymond MJ, Pilotte NS, Foreman MM, Tilders FJH (1980) Some aspects of hypothalamic and hypophysial secretion in aging rats. Peptides 1:135-139.

Reymond MJ, Porter JC (1981) Secretion of hypothalamic dopamine into pituitary stalk blood of aged female rats. Brain Res Bull 7: $69-73$. 
Sanchez HL, Silva LB, Portiansky EL, Goya RG, Zuccolilli GO (2003) Impact of very old age on hypothalamic dopaminergic neurons in the female rat: a morphometric study. J Comp Neurol 458:319-325.

Sanchez HL, Silva LB, Portiansky EL, Hereñu CB, Goya RG, Zuccolilli GO (2008) Dopaminergic mesencephalic systems and motor performance in very old rats. Neuroscience 154:1598-1606.

Shimohama S, Sawada H, Kitamura Y, Taniguchi T (2003) Disease model: Parkinson's disease. Trends Mol Med 9:360-365.

Tillet Y, Kitahama K (1998) Distribution of central catecholaminergic neurons: a comparison between ungulates, humans and other species. Histol Histopathol 13:1163-1177.

Tomac A, Lindqvist E, Lin LFH, Ögrenn SO, Young D, Hoffer BJ, Olson $L$ (1995) Protection and repair of the nigrostriatal dopaminergic system by GDNF in vivo. Nature 373:335-339.

Trupp M, Belluardo N, Funakoshi H, Ibanez CF (1997) Complementary and overlapping expression of glial cell line-derived neurotrophic factor (GDNF), c-ret proto-oncogene, and GDNF receptor-a indicates multiple mechanisms of trophic actions in the adult Rat CNS. J Neurosci 17:3554-3567.

Tumer N, Scarpace PJ, Dogan MD, Broxson CS, Matheny M, Yurek DM, Peden CS, Burger C, Muzyczka N Mandel RJ (2006) Hypothalamic rAAV-mediated GDNF gene delivery ameliorates agerelated obesity. Neurobiol Aging 27:459-470.

Valtin H (1992) Genetic models of diabetes insipidus. In: Handbook of physiology (Windhager EE, ed), pp 1281-1316. New York, NY: Oxford University Press.

West MJ, Slomianka L, Gundersen HJ (1991) Unbiased stereological estimation of the total number of neurons in the subdivisions of the rat hippocampus using the optical fractionator. Anat Rec 231:482497.

Zhang Z, Miyoshi Y, Lapchak PA, Collins F, Hilt D, Lebel C, Kryscio R, Gash DM (1997) Dose response to intraventricular glial cell linederived neurotrophic factor administration in parkinsonian monkeys. J Pharmacol Exp Ther 282:1396-1401. 